\title{
Effects of settler size and density on early post- settlement survival of Ciona intestinalis in the field
}

\author{
Dustin J. Marshall*, Michael J. Keough \\ Zoology Department, The University of Melbourne, Victoria 3010, Australia
}

\begin{abstract}
Effects of variation in larval quality on post-metamorphic performance in marine invertebrates are increasingly apparent. Recently, it has been shown that variation in offspring size can also strongly affect post-settlement survival, but variation in environmental conditions can mediate this effect. The quality of habitat into which marine invertebrate larvae settle can vary markedly, and 1 influence on quality is the number of conspecifics present. We tested the effects of settler size and settler density on early ( $1 \mathrm{wk}$ after settlement) post-settlement survival in the field for the solitary ascidian Ciona intestinalis. Larger settlers survived better than smaller settlers, within and among groups of siblings. Increases in the density of settlers decreased survival, but the density-dependent effects were much stronger for smaller settlers. We suggest that larger settlers are better able to cope with intra-specific competition because they have greater energetic reserves or a greater capacity to feed than smaller settlers.
\end{abstract}

KEY WORDS: Offspring size $\cdot$ Carry-over effects $\cdot$ Recruitment $\cdot$ Density-dependence

\section{INTRODUCTION}

It is becoming apparent that adult performance is strongly coupled to larval nutritional condition in a wide range of marine taxa (Pechenik et al. 1998, Einum \& Fleming 1999, Marshall et al. 2003a). In species with planktotrophic larvae, the amount of food available to larvae affects their survival and growth as juveniles and adults (Pechenik et al. 1998, Phillips 2002). In lecithotrophic species, larvae that have their metamorphosis experimentally delayed, and presumably their nutritional reserves depleted, have lower growth rates in the field (Wendt 1998, Marshall et al. 2003a). These studies suggest that the amount of energy available to newly metamorphosed juveniles will strongly affect their chances of success. A few studies have also shown that the initial provisioning of lecithotrophic offspring affects their post-metamorphic performance in the field. Moran \& Emlet (2001) found that initial size of juvenile Nucella ostrina gastropods strongly affected survival and growth in the field. Similarly, Einum \& Fleming (1999) found strong effects of initial egg size on the survival and growth of brown trout Salmar trutta. Interestingly, both these studies found that the effects of offspring size were mitigated by the local environment; Einum \& Fleming (1999) found that the advantages of larger offspring size were increased in a harsher environment, while Moran \& Emlet (2001) found the converse. This interaction between offspring size and the environment suggests that any study addressing the effects of offspring size on offspring fitness should consider variation in environmental quality (see also Fox 2000).

The habitat into which marine invertebrate larvae settle can vary in quality according to a range of factors, such as the availability of food and suitable microhabitats, predation pressure and competition intensity (reviewed in Gosselin \& Qian 1997, Hunt \& Scheibling 1997). Variation in the density of newly settled individuals also has strong (negative and positive) effects on post-metamorphic survival and growth of some sessile marine invertebrate species (Bertness 1989, Gosselin \& Qian 1997, Hunt \& Scheibling 1997), although effects are weak in others (Keough 1986). Given that variation in the settlement densities of marine invertebrates can be extreme (Underwood \& 
Keough 2001), it seems pertinent to test whether the effects of offspring size are influenced by settler density in a sessile marine invertebrate.

Here we examine the effects of settler size on early post-settlement survival for the solitary ascidian Ciona intestinalis in the field. The larvae of $C$. intestinalis are lecithotrophic and consequently the size of settlers reflects initial maternal investment. In addition to examining the effects of offspring size alone, we also examined how the effects of offspring size are mediated by variation in the density of settlers. We manipulated the density of $C$. intestinalis settlers on artificial settlement plates in the laboratory, and then placed these plates into the field for $1 \mathrm{wk}$ prior to assessing survivorship. For the first experiment, we predicted that larger settlers would have higher survivorship than smaller settlers. For the experiment where we varied settler size and settler density, we predicted that the difference in survivorship of larger and smaller settlers would be affected by settler density, but we had no a priori hypotheses about the direction of this effect.

\section{MATERIALS AND METHODS}

We collected reproductively mature Ciona intestinalis of a range of sizes from the undersides of floating pontoons at St. Kilda Marina, Victoria, Australia during February 2002. The adults were kept in aquaria with recirculating seawater at $\sim 15^{\circ} \mathrm{C}$ and all experiments were done using the gametes of these individuals within 1 wk of collection. We collected gametes by making a small slit in the oviduct or sperm duct, and gently sucking out the gametes using a pipette. Once in the oviduct, $C$. intestinalis eggs do not develop further. We collected either sperm or eggs from a single individual to minimise the chances of self-fertilisation. For the first and third experiments, we pooled the eggs from 5 individuals and fertilised the eggs by gently rinsing the eggs repeatedly in a dilute $\left(\sim 10\right.$ sperm $\left.\mu l^{-1}\right)$ sperm solution. This minimised the chances of polyspermy, while ensuring as many eggs were fertilised as possible. The sperm solution was obtained from a single adult so all the larvae in the first and third experiments were at least half-siblings. For the second experiment, we only used the eggs from a single individual; consequently all the larvae in the second experiment were full siblings.

In all 3 experiments fertilisation success exceeded $95 \%$. The developing embryos were kept in 11 glass beakers with $800 \mathrm{ml}$ of filtered $(0.45 \mu \mathrm{m})$ seawater at room temperature $\left(20^{\circ} \mathrm{C}\right)$. The seawater was replaced twice in an $18 \mathrm{~h}$ period between fertilisation of the eggs and 'hatching' of the larvae. Once most (> $80 \%$ ) of the larvae had hatched and were actively swimming in the beakers, we placed 30 to 60 larvae into each petri dish (plastic petri dishes, $90 \mathrm{~mm}$ diameter, $10 \mathrm{~mm}$ depth). The petri dishes had been pre-roughened with sandpaper and left in seawater aquaria for $24 \mathrm{~h}$ prior to use. Five $\mathrm{h}$ after placing the larvae into the petri dishes, we rinsed each petri dish gently with seawater to remove any unattached larvae, leaving only those larvae that had firmly attached to the petri dish and begun metamorphosis. We then placed the petri dishes in aquaria with recirculating seawater at $15^{\circ} \mathrm{C}$, and allowed the attached larvae to develop and metamorphose for $24 \mathrm{~h}$.

Twenty-four $\mathrm{h}$ after settlement, the settlers had not yet begun to feed but had lengthened and were beginning to develop feeding structures. The size of settlers was estimated as the longest length of the settler, not including the thin stalk by which the settlers were attached to the substrate. Pilot studies indicated that this was a reliable measure of settler volume and dry weight (D.J.M. unpubl. data). We measured individual settlers to the nearest $10 \mu \mathrm{m}$ using an ocular micrometer (80× magnification), and classed larvae as either 'small', 'medium' or 'large' $(<320,320$ to 370 and $>370 \mu \mathrm{m}$, respectively). The small and large size classes corresponded to the first and third quartiles of the range of settler sizes that were observed throughout the study, and reflect the broad range of settler sizes observed in the field (D.J.M. unpubl. data).

For the first and second experiments, after we had classed the settlers into appropriate size groups, we removed all the 'medium' sized settlers using a pair of fine forceps. We then removed haphazardly selected large and small settlers so that, within each petri dish, there were approximately equal numbers of large and small settlers (i.e. the difference in the number of large and small settlers was never greater than 1 within any petri dish). The number of settlers that were present in each size group for each petri dish ranged between 3 and 5.

For the third experiment, once we had allocated the settlers into the appropriate size classes, we noted the number of medium-sized settlers on each petri dish but allowed them to remain. We then adjusted the number of large and small settlers as in the first 2 experiments. The number of medium-sized settlers on each petri dish ranged between 0 and 41, and this range of settler densities is not uncommon for natural settlement densities in the field at Breakwater Pier (Johnston 2001). We allowed the number of mediumsized settlers to vary in order to examine the effects of density, because we could not obtain large and small settlers in sufficient numbers in order to conduct the experiment with the appropriate number of treatments. For the third experiment, there were 3 to 4 settlers in each of the large and small size classes. 
For all 3 experiments, care was taken to ensure that no settlers were closer than $10 \mathrm{~mm}$ to their nearest neighbour. If 2 settlers were too close, 1 was selected haphazardly and removed.

For all 3 experiments, once we had classed settlers into appropriate size classes and adjusted the density of settlers in each petri dish appropriately, we marked the position of each settler on the underside of the petri dish using a pencil. We carefully drilled an $8 \mathrm{~mm}$ diameter hole in the centre of the petri dish using a handpowered drill. The petri dishes were then transported to the field site (20 min from the laboratory) in insulated aquaria with $10 \mathrm{l}$ of seawater. No settlers died during handling, petri dish preparation or transportation and deployment into the field.

The petri dishes were deployed into the field at Breakwater Pier, Williamstown, Australia. The fauna of the pier has been well described and Ciona intestinalis is a common component of the fouling community (Keough \& Raimondi 1995). The pier is sheltered from the prevailing weather by a large rocky breakwater. We attached the petri dishes to large $(900 \times 900 \mathrm{~mm})$ Perspex sheets using stainless steel bolts. The backing plates were then suspended from the pier face down (to reduce the effects of sedimentation and light), $2 \mathrm{~m}$ below the mean low-water mark. For the first experiment, we used 2 backing plates, and for the second and third experiments we used a single backing plate for each. The first experiment was deployed $(\mathrm{n}=19$ petri dishes) into the field on 19 February 2002, the second experiment was deployed ( $\mathrm{n}=13$ petri dishes) on 28 February 2002, and the third experiment $(\mathrm{n}=15$ petri dishes) on 4 March 2002. For each experiment, we assessed mortality $1 \mathrm{wk}$ after the experiments were deployed in the field. To assess mortality, the plates were hauled out of the water and examined under a dissecting microscope (magnification 40x) in the field. In each experiment, settlers were either present or had disappeared completely, leaving no trace, and consequently settlers were scored as 'dead' if the settler was not present, and 'alive' if the settler was present. Given that any settlers that were dislodged from the petri dish were highly unlikely to survive, we considered them to have died despite having no direct evidence that this was the case.

For the first and second experiments, we analysed the effect of the size of settlers on their survivorship using a randomised complete-block design, where the proportion of settlers surviving within each size class of each petri dish was the dependent variable, settler size was a fixed factor, and petri dish was a random, blocking factor. For the first experiment, the effects of backing plate could have been included as an additional, random factor. However, when we ran a model with the effect of backing plate included, there was no interaction between settler size and backing plate ( $p=0.273$ ), and the main effect of backing plate explained little of the variation. As backing plate was of no biological interest, we removed it from the model completely (Quinn \& Keough 2002). For the third experiment, we again analysed our data using a randomised complete block design, but also included the density of medium-sized settlers as a covariate. For each experiment, the response variable was proportion data, and some values were greater than 0.9 and less than 0.1. Although it has been suggested that this data should be square-root-arcsine-transformed (e.g. Quinn \& Keough 2002), this transformation did not improve the distribution of data and did not change the significance of any of the tests here. Consequently, we analyse and present the untransformed data. It should be pointed out that the error terms presented in Fig. 1 are appropriate for the analyses used to examine the effects of settler size (see Quinn \& Keough 2002, p. 506-507).

\section{RESULTS}

Mortality was high after 1 wk in the field, and more than $50 \%$ of all settlers that were transplanted into the field disappeared in the first and second experiments. In the third experiment, approximately $30 \%$ of all settlers disappeared in the first week. As mentioned above, where settlers had disappeared, there was no trace of them left on the petri dishes. No micrograzers or potential predators (e.g. Osman \& Whitlatch 1995) were observed on the petri dishes, and there were no obvious scrapings or markings on the petri dishes after $1 \mathrm{wk}$. Various polychaete worms and the encrusting bryozoan Watersipora subtorquata settled on the petri dishes and occupied approximately $10 \%$ of the available free space.

Larger Ciona intestinalis settlers had higher survivorship in the field than smaller settlers, regardless of whether or not they were full siblings (Table 1). In the first experiment, after $1 \mathrm{wk}$, the proportion of larger settlers that remained was approximately double that of the smaller settlers (Fig. 1a). The size of settlers also influenced survivorship in the field within a single sibship of settlers, with the proportion of larger settlers remaining being more than double that of their smaller siblings (Table 1, Fig. 1b).

In the third experiment, the size and density of settlers affected survivorship, and their effects were dependent on each other (Table 2, Fig. 2). Specifically, the difference in survival of large and small settlers increased with density (correlation between difference in survival between the 2 size classes and density: $r=0.524$, Fig. 2). We were concerned that 2 replicates 
Table 1. Ciona intestinalis. Effect of the size of settlers on survivorship after $1 \mathrm{wk}$ in the field at Breakwater Pier, Victoria, Australia. Newly metamorphosed C. intestinalis $>370 \mu \mathrm{m}$ were classed as large, and small if $<320 \mu \mathrm{m}$. Expt 1 used larvae from multiple $(n=5)$ dams and a single sire. Expt 2 used larvae from only a single dam and a single sire

\begin{tabular}{|lrccc|}
\hline Source & df & Mean-square & $F$ & $p$ \\
\hline Expt 1 & & & & \\
$\quad$ Petri dish & 18 & 2077 & 2.75 & 0.019 \\
$\quad$ Settler size & 1 & 5872 & 7.77 & 0.012 \\
Error & 18 & 755 & & \\
Expt 2 & & & & \\
$\quad$ Petri dish & 12 & 0.082 & 1.06 & 0.464 \\
Settler size & 1 & 1.198 & 15.39 & 0.002 \\
Error & 12 & 0.078 & & \\
\hline
\end{tabular}

with the highest density could unduly influence our findings because of large leverage. However, we repeated the analysis, omitting the 2 most extreme density values, and still found a significant difference in the slopes of survival across settler densities for larger and smaller settlers (density $\times$ size interaction: $\left.F_{1,11}=5.098, \mathrm{p}=0.045\right)$.

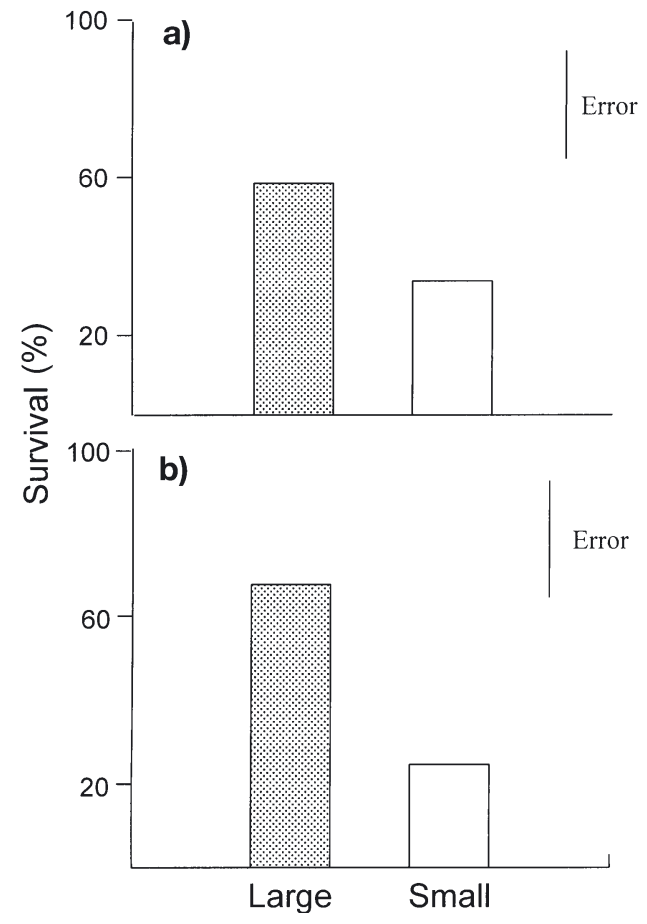

Fig. 1. Ciona intestinalis. Effects of settler size on survival after $1 \mathrm{wk}$ in the field using larvae from (a) multiple and (b) single dams. Bars indicate mean survival. Large (>370 $\mu \mathrm{m})$ settlers are indicated by shaded bars, small $(<320 \mu \mathrm{m})$ settlers by open bars. Error = square root of the mean square of the ANOVA error term, used to test effects of size
Table 2. Ciona intestinalis. Effect of size of settlers and the density of settlers on survivorship after $1 \mathrm{wk}$ in the field at Breakwater Pier, Victoria, Australia. Newly metamorphosed C. intestinalis $>370 \mu \mathrm{m}$ were classed as large, and small if $<320 \mu \mathrm{m}$

\begin{tabular}{|lrccc|}
\hline Source & df & Mean-square & $F$ & $p$ \\
\hline Density & 1 & 7632 & 12.02 & 0.004 \\
Petri dish & 13 & 635 & & \\
Size & 1 & 1581 & 3.522 & 0.083 \\
Size $\times$ Density & 1 & 2204 & 4.908 & 0.045 \\
Error & 13 & 5837 & & \\
\hline
\end{tabular}

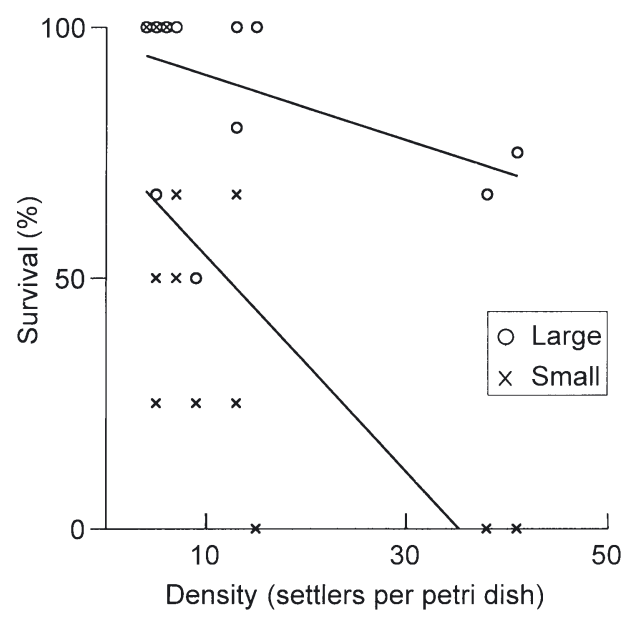

Fig. 2. Ciona intestinalis. Effects of settler size and settler density on survival after $1 \mathrm{wk}$ in the field. Each circle represents proportion of large $(>370 \mu \mathrm{m})$ settlers surviving $(\mathrm{n}=15)$ and each cross represents proportion of small $(<320 \mu \mathrm{m})$ settlers ( $\mathrm{n}=15$ ) surviving on each settlement plate. Lines indicate lines of best fit for both size classes

\section{DISCUSSION}

In all 3 experimental trials, larger Ciona intestinalis settlers had higher post-settlement survivorship than smaller settlers in the field. The effect of settler size on post-metamorphic survival was consistent within and among sibships of settlers. Although we did not measure post-settlement survival after the first week, it is likely that the effects of settler size observed here will influence the subsequent distribution of juveniles. For a range of species, early (days to weeks) postsettlement mortality determines the final distribution of the adults (reviewed in Hunt \& Scheibling 1997). Larger settlers may also have greater post-settlement growth than smaller settlers because they begin sessile life with more nutritional reserves (e.g. Moran \& Emlet 2001). Furthermore, if larger settlers had larger branchial baskets, then larger settlers may have a greater capacity to feed than smaller settlers, main- 
taining any initial advantages in size (e.g. Wendt 1996, 1998, Marshall et al. 2003a).

Mortality was strongly density-dependent in smaller settlers, but for larger settlers the effects of density were much weaker. It appears that larger settlers are better able to cope with the negative effects of increases in the density of settlers. It is unclear why increases in settler density resulted in decreased survival. Settlers were separated by at least $10 \mathrm{~mm}$ before being deployed in the field, and did not grow enough in a single week to come into contact with one another. It is possible that density affected postsettlement mortality due to predation or intra-specific competition. It may be that increases in settler density increase the chances of predation, and larger settlers are more likely to survive. However, such size-specific predation seems unlikely given the relatively small differences in settler size (Pechenik 1999), and we observed no predators on the petri dishes when they were hauled from the water. Alternatively, smaller settlers may be more likely to be dislodged, but this too seems unlikely given that larger settlers also disappeared in higher proportions when density was increased. We believe it is more likely that the effects of density on smaller settlers are due to the effects of non-contact intra-specific competition. Few studies have identified mechanisms for non-contact competition in sessile marine invertebrates, although there is circumstantial evidence that competition for food is the most likely mechanism (reviewed in Dalby 1995). Given that larger settlers are likely to have greater energetic reserves (Moran \& Emlet 2001), it seems likely that food limitation and starvation are the likely sources of the increased mortality for smaller settlers. Size-specific competitive ability has been found in a range of other sessile marine invertebrates (Connell 1961, Russ 1982, Sebens 1982), although few studies have examined competition very soon after settlement. Regardless of the mechanism behind the effect of density, it is clear that the effects of offspring size are strongly exacerbated by increases in the density of conspecific individuals.

The quality of the environment into which Ciona intestinalis larvae settle is strongly affected by the density of conspecific individuals. This study confirms that the effects of offspring size are highly dependent on the quality of the environment. In contrast to Moran \& Emlet (2001), in harsher conditions we found that the benefits of increased offspring size were increased. The source of increased mortality in Moran \& Emlet's (2001) study was thought to be thermal stress; here we believe it to be competition for food. Clearly, some sources of mortality are more likely to be size-dependent than others (e.g. storms, see Marshall et al. 2003b), but it remains difficult to predict which environmental stresses will increase the advantages of increased offspring investment, and vice versa.

It is apparent that offspring size can affect adult performance as profoundly as delays in metamorphosis. Optimality models of the effects of egg/larval size in marine invertebrates tend to consider the effects of offspring size on fertilisation success, planktonic duration and mortality (e.g. Vance 1973, Levitan 1993). A growing body of literature suggests that larval size/quality will also affect the post-settlement survivorship, growth and competitive ability of the adults (Jarrett \& Pechenik 1997, Pechenik et al. 1998, Phillips 2002, Marshall et al. 2003a,b). Given the strength of these observed effects, it may be necessary to incorporate them into any model considering egg size optimality in marine invertebrates. More generally, many offspring size optimality models fail to consider variation in the quality of the natal environment (e.g. Smith \& Fretwell 1974, but see Hendry et al. 2001). It seems likely that the strength of selection for offspring of different sizes is likely to vary with environmental quality, and models should reflect this accordingly.

In previous papers, we have identified 2 sources of variation in larval size, covariation between maternal body size and egg size, and variation in the fertilising sperm environment (Marshall et al. 2000, 2002). We have also found that the size of larvae settling in the field can be highly variable (Marshall \& Keough 2003b). Many other studies have identified substantial intraspecific variation in egg/larval size within lecithotrophic marine invertebrate species (e.g. George 1996, Jones et al. 1996, Bertram \& Strathmann 1998, Phillips \& Gaines 2002). Clearly, the relationship between the number of settlers and the number of recruits is likely to vary according to both the density and size of settlers. This study highlights the consequences of this variation for post-settlement survival and competitive ability. An interesting challenge will be to examine how variation in larval size and settler density affect post-settlement growth and reproduction.

\section{LITERATURE CITED}

Bertness MD (1989) Intraspecific competition and facilitation in a northern acorn barnacle population. Ecology 70: 257-268

Bertram DF, Strathmann RR (1998) Effects of maternal and larval nutrition on growth and form of planktonic larvae. Ecology 79:315-327

Connell JH (1961) Effects of competition, predation by Thais lapillus, and other factors on natural populations of the barnacle Balanus balanoides. Ecol Monogr 31:61-104

Dalby JE (1995) Consequences of aggregated living in the ascidian Pyura stolonifera: evidence for non-contact intraspecific competition. Mar Freshw Res 46:1196-1199

Einum S, Fleming IA (1999) Maternal effects of egg size in 
brown trout (Salmo trutta): norms of reaction to environmental quality. Proc R Soc Lond B 266:2095-2100

Fox CW (2000) Natural selection on seed-beetle egg size in nature and the laboratory: variation among environments. Ecology 81:3029-3035

George SB (1996) Echinoderm egg and larval quality as a function of adult nutritional state. Oceanol Acta 19:297-308

Gosselin LA, Qian PY (1997) Juvenile mortality in benthic marine invertebrates. Mar Ecol Prog Ser 146:265-282

Hendry AP, Day T, Cooper AB (2001) Optimal size and number of propagules: allowance for discrete stages and effects of maternal size on reproductive output and offspring fitness. Am Nat 157:387-407

Hunt HL, Scheibling RE (1997) Role of early post-settlement mortality in recruitment of benthic marine invertebrates. Mar Ecol Prog Ser 155:269-301

Jarrett JN, Pechenik JA (1997) Temporal variation in cyprid quality and juvenile growth capacity for an intertidal barnacle. Ecology 78:1262-1265

Johnston EL (2001) Effect of transient copper pollution events on the ecology of marine epifaunal assemblages. $\mathrm{PhD}$ thesis, University of Melbourne

Jones HL, Todd CD, Lambert WJ (1996) Intraspecific variation in embryonic and larval traits of the dorid nudibranch mollusc Adalaria proxima (Alder and Hancock) around the northern coasts of the British Isles. J Exp Mar Biol Ecol 202:29-47

Keough MJ (1986) The distribution of the bryozoan Bugula neritina on seagrass blades: settlement growth and mortality. Ecology 67:846-857

Keough MJ, Raimondi PT (1995) Responses of settling invertebrate larvae to bioorganic films: effects of different types of films. J Exp Mar Biol Ecol 185:235-253

Levitan DR (1993) The importance of sperm limitation to the evolution of egg size in marine invertebrates. Am Nat 141: 517-536

Marshall DJ, Keough MJ (2003) Variation in the dispersal potential of non-feeding larvae: the desperate larva hypothesis and larval size. Mar Ecol Prog Ser 255:145-153

Marshall DJ, Styan CA, Keough MJ (2000) Intraspecific covariation between egg and body size affects fertilisation kinetic in broadcast spawning marine invertebrates. Mar Ecol Prog Ser 195:305-309

Marshall DJ, Styan CA, Keough MJ (2002) Sperm environment affects offspring quality in broadcast spawning marine invertebrates. Ecol Lett 5:173-176

Marshall DJ, Pechenik JA, Keough MJ (2003a) Larval activity

Editorial responsibility: Charles Peterson (Contributing Editor), Morehead City, North Carolina, USA levels and delayed metamorphosis affect post-larval performance in the colonial ascidian Diplosoma listerianum. Mar Ecol Prog Ser 246:153-162

Marshall DJ, Bolton TF, Keough MJ (2003b) Offspring size affects post-metamorphic performance in a colonial marine. Ecology (in press)

Moran AL, Emlet RB (2001) Offspring size and performance in variable environments: field studies on a marine snail. Ecology 82:1597-1612

Osman RW, Whitlatch RB (1995) Predation on early ontogenic life stages and its on recruitment into a marine epifaunal community. Mar Ecol Prog Ser 117:111-126

Pechenik JA (1999) On the advantages and disadvantages of larval stages in benthic marine invertebrate life cycles. Mar Ecol Prog Ser 177:269-297

Pechenik JA, Wendt DE, Jarrett JN (1998) Metamorphosis is not a new beginning. Bioscience 48:901-910

Phillips NE (2002) Effects of nutrition-mediated larval condition on juvenile performance in a marine mussel. Ecology 83:2562-2574

Phillips NE, Gaines SD (2002) Spatial and temporal variability in size at settlement of intertidal mytilid mussels from around Pt. Conception, California. Invertebr Reprod Dev 41:1-3

Quinn GP, Keough MJ (2002) Experimental design and data analysis for biologists. Cambridge University Press, Melbourne

Russ GR (1982) Overgrowth in a marine epifaunal community: competitive hierarchies and competitive networks. Oecologia 53:12-19

Sebens KP (1982) Competition for space: growth rate, reproductive output, and escape in size. Am Nat 120:189-197

Smith CC, Fretwell SD (1974) The optimal balance between size and number of offspring. Am Nat 108:499-506

Wendt DE (1996) Effect of larval swimming duration on success of metamorphosis and size of the ancestrular lophophore in Bugula neritina (Bryozoa). Biol Bull 191:224-233

Wendt DE (1998) Effect of larval swimming duration on growth and reproduction of Bugula neritina (Bryozoa) under field conditions. Biol Bull 195:126-135

Underwood AJ, Keough MJ (2001) Supply-side ecology—the nature and consequences of variations in recruitment of intertidal organisms. In: Bertness MD, Gaines SD, Hay ME (eds) Marine community ecology. Sinauer, Sunderland, MA, p 183-200

Vance RR (1973) On reproductive strategies in marine benthic invertebrates. Am Nat 107:339-35

Submitted: December 9, 2002; Accepted: May 27, 2003

Proofs received from author(s): August 22, 2003 